\title{
Lymphoproliferative Disorder
}

National Cancer Institute

\section{Source}

National Cancer Institute. Lymphoproliferative Disorder. NCI Thesaurus. Code C9308.

A disorder characterized by proliferation of lymphocytes at various stages of

differentiation. Lymphoproliferative disorders can be neoplastic (clonal, as in lymphomas

and leukemias) or reactive (polyclonal, as in infectious mononucleosis). 